\title{
The effect of amino acid imbalance on nitrogen retention (biological value) in rats
}

\author{
BY B. O. EGGUM, K. E. BACH KNUDSEN AND INGEBORG JACOBSEN \\ National Institute of Animal Science, Department of Animal Physiology and Chemistry, \\ Rolighedsvej 25, DK-1958 Copenhagen, Denmark
}

(Received 25 March 1980 - Accepted 28 August 1980)

\begin{abstract}
1. Three series of nitrogen balance experiments were performed with growing rats to test the effect of amino acid imbalance on protein utilization. In Expt 1 egg protein was fed as a basal diet and supplemented with one amino acid at a time in the amounts originally found in egg protein. In Expt 2 the procedure was repeated with a barley diet, and in Expt $3 \mathrm{egg}$ and potato proteins were fed together in various combinations.

2. Doubling the single amino acids, especially arginine, in an egg-protein diet reduced biological value (BV) markedly. Also the branched-chain and the basic amino acids reduced Bv significantly. In the barley-based diets negative effects were also observed when the concentration of the single amino acid was doubled. However, it was assumed that the observed deleterious effects of amino acid excess were partly due to an exaggerated lysine deficiency in the barley protein when non-limiting amino acids were added.

3. The results with various combinations of egg and potato proteins showed that as potato protein was increased true protein digestibility decreased linearly, whereas BV decreased curvilinearly. Maximum protein utilization was obtained with egg protein alone.
\end{abstract}

Since amino acids in general enter into a variety of alternative metabolic pathways it has been widely assumed that any surplus ingested and not subsequently used for protein synthesis exerts no adverse effects. However, nowadays there is a great tendency to appreciate the importance of the over-all amino acid balance in determining protein quality and the fact that ideal foods should not merely contain adequate quantities of each of the amino acids but also the importance of avoiding excess when ever possible.

When amino acid imbalance is produced in chicks, appetite is adversely affected but the mechanism by which the altered amino acid pattern affects the appetite-regulating centre is not yet understood (Harper et al. 1970; Woodham \& Deans, 1977). Experiments along these lines have been performed with chickens and have supported the hypothesis that diets formulated to minimize excess of amino acids over the chicks' known requirements wou'd improve the efficiency of protein and energy utilization especially when birds were under stress (Waldroup et al. 1976). The removal of amino acid deficiencies alone is not sufficient to ensure that a given mixture of proteins produces optimum performance in growing chickens. In some instances the relative proportions of essential amino acids may be of greater significance than the absolute amounts because of the complex relationship between amino acids (Brewer et al. 1978). However, according to Harper (1974) animals receiving diets that meet their requirements for all amino acids tolerate substantial amounts of imbalanced amino acid mixtures without showing ill effects. Therefore, disproportionate amounts of amino acids encountered naturally in foods should not commonly result in adverse effects. Adverse effects observed experimentally are usually severe only when the protein content of the diet is low or the disproportion is very great. On the other hand the work of Kofrányi \& Jekat (1964) which is further discussed by Kofrányi (1972), clearly demonstrates that there exists a distinct minimum for protein requirement of young men when a certain combination of two protein sources is fed. 
The present work was planned to study the effect of an induced excess of a single amino acid on nitrogen retention in growing rats. Furthermore, two protein sources, egg and potatoes, were combined in various proportions to test the hypothesis of whether there exists a distinct optimum combination of these two protein sources for fast growing rats.

\section{EXPERIMENTAL}

Diets

Two protein sources of different protein quality, freeze-dried and diethyl ether-extracted egg protein and barley (Expts 1 and 2 respectively) were used to study the effect of amino acid excess on protein utilization. Each of the individual eighteen amino acids were added to the diets, one at a time, in a concentration corresponding to the amounts in the respective proteins, i.e. a $100 \%$ increase. In a third Expt eleven combinations of egg and potato proteins were fed. Eggs were freeze-dried and diethyl ether-extracted before use and potatoes were boiled, skinned and freeze-dried before being made into flour. The total dietary protein level $(\mathrm{N} \times 6.25)$ was fixed at $94 \mathrm{~g} / \mathrm{kg}$ in order to keep protein as a limiting factor in the diets.

\section{Animals and feeding}

The experimental procedure has been described by Eggum (1973). Groups of five Wistar male rats weighing approximately $70 \mathrm{~g}$ were used in the experiments with preliminary periods of $4 \mathrm{~d}$ and balance periods of $5 \mathrm{~d}$. There were eleven groups per experiment. Each animal received $150 \mathrm{mg} \mathrm{N}$ and $10 \mathrm{~g}$ dry matter (DM) daily throughout the preliminary and the balance periods. The $\mathrm{N}$ content was adjusted by using an $\mathrm{N}$-free mixture composed mainly of autoclaved potato starch, sucrose, oil, cellulose powder, vitamin and mineral mixtures.

\section{Chemical analyses}

Diets were analysed for DM, $\mathbf{N}$ and amino acids. Faeces and urine were analysed for $\mathbf{N}$. DM and $\mathbf{N}$ were determined according to standard methods (Association of Official Agricultural Chemists, 1965). Amino acid analyses were carried out according to Mason et al. (1980) and Eggum (1968).

\section{Statistical analyses}

The results from the imbalance experiments were tested for differences in means by one-way analyses of variance according to the following model:

$$
X_{i j}=\mu+\alpha_{i}+\epsilon_{i j} \text {. }
$$

Where $i$, number of treatments $1-a(a=19) ; j$, number of replicates $1-b(b=5) ; X_{i j}$, dependent variable (i.e. $\mathrm{BV}$ ); $\mu$, location parameter common to all observations; $\alpha_{i}$, effect

of treatment no. $i \sum_{i} \alpha_{i}=0 ; \epsilon_{i j}$, normal distributed random variable with means zero and variance $\delta^{2}$.

Treatment means (diets 1-18) differing significantly from the corresponding basal diet (treatment no. 19) were identified by a $t$ test. The test variables were:

$$
t_{i}=\frac{\bar{x}_{i}-\bar{x}_{1 \mathrm{~g}}}{\sqrt[s]{\frac{2}{n}}}
$$

Where $x_{i}$, unbiased estimate of treatment no. i $\left(\mu+\alpha_{i}\right) ; \bar{x}_{19}$, unbiased estimate of BV of egg or barley protein; $s$, unbiased estimate of $\delta$ :

$$
\sqrt{\frac{\sum_{i j} \epsilon_{i j}^{2}}{a(b-1)}}
$$


Table 1. Expts 1 and 2. Amino acid composition ( $/ \mathrm{kg}$ protein (nitrogen $\times 6 \cdot 25)$ ) of potato, egg and barley protein and the biological value (BV) of egg and barley proteins when the concentration of the single amino acid is doubled

\begin{tabular}{|c|c|c|c|c|c|}
\hline \multirow[t]{2}{*}{ Protein source... } & \multirow[t]{2}{*}{ Potato } & \multicolumn{2}{|c|}{ Egg } & \multicolumn{2}{|c|}{ Barley } \\
\hline & & & BV & & BV \\
\hline Aspartic acid & $215 \cdot 0$ & $105 \cdot 0$ & 0.98 & 54.8 & $0.68 * *$ \\
\hline Threonine & 34.9 & $44 \cdot 7$ & 0.99 & 33.9 & 0.70 \\
\hline Serine & 35.0 & $71 \cdot 2$ & 0.99 & 40.7 & $0.69 *$ \\
\hline Glutamic acid & $164 \cdot 1$ & 149.9 & 0.99 & $244 \cdot 2$ & $0.64^{* *}$ \\
\hline Proline & $35 \cdot 7$ & $38 \cdot 8$ & 0.98 & $106 \cdot 5$ & $0.66^{* *}$ \\
\hline Valine & 44.4 & 62.7 & $0.97^{*}$ & 47.0 & $0.67^{* *}$ \\
\hline Glycine & 30.7 & $33 \cdot 7$ & 0.98 & $38 \cdot 8$ & 0.70 \\
\hline Alanine & $31 \cdot 9$ & $58 \cdot 4$ & 0.98 & $39 \cdot 3$ & $0.69^{*}$ \\
\hline Isoleucine & $35 \cdot 6$ & $54 \cdot 8$ & $0.97^{* *}$ & $35 \cdot 4$ & 0.70 \\
\hline Leucine & 57.9 & $89 \cdot 3$ & $0.97^{*}$ & 68.4 & $0.68^{* *}$ \\
\hline Tyrosine & 33.6 & $41 \cdot 2$ & $0.97 * *$ & 29.9 & 0.70 \\
\hline Phenylalanine & 39.4 & $56 \cdot 2$ & 0.99 & $47 \cdot 7$ & 0.71 \\
\hline Lysine & $51 \cdot 5$ & 68.7 & $0.96^{* *}$ & 33.7 & $0.80^{* *}$ \\
\hline Histidine & 16.0 & $2 \cdot 47$ & $0.97^{\star}$ & $21 \cdot 2$ & 0.70 \\
\hline Arginine & 50.7 & 65.9 & $0.92 * *$ & 48.4 & $0.66 * *$ \\
\hline Methionine & 16.5 & $33 \cdot 5$ & 0.98 & $16 \cdot 8$ & 0.69 \\
\hline Cystine & 11.8 & $22 \cdot 3$ & $0.97^{*}$ & $19 \cdot 3$ & 0.69 \\
\hline Tryptophan & $11 \cdot 5$ & 15.9 & 0.98 & $11 \cdot 5$ & 0.71 \\
\hline No addition & - & - & 0.99 & 一 & 0.71 \\
\hline$F$ ratio (df 18,76 ) & & & $15 \cdot 324^{* * *}$ & & $54 \cdot 817^{* * *}$ \\
\hline Barlett's test (df 18) & & & $28.683 \mathrm{NS}$ & & $22.623 \mathrm{NS}$ \\
\hline SE & & & 0.427 & & 0.419 \\
\hline
\end{tabular}

NS, non significant.

$* P<0.05, * * P<0.01, * * P<0.001$.

$n$, number of replicates (i.e. 5).

For both protein sources the zero hypothesis was tested Ho: $\mu_{i}=\mu_{19}$ and the alternative hypothesis $\mathrm{H}_{i}: \mu_{i}=\mu_{19}$. The $t$ values at $P<0.05(2.96)$ and $P<0.01$ (3.54) levels were identified according to tables by Dunnett (1964) for multiple comparisons with a control group.

The true protein digestibility (TD) of the combinations of egg and potato proteins (Expt 3) were analysed after the linear model:

$$
Y_{i}=\beta_{0}+\beta_{1} X_{i}+\epsilon_{i}
$$

Where $i$, number of treatments; $Y_{i}$, dependent variable (i.e. TD); $X_{i}$, independent variable; $\beta_{o}$, intercept $; \beta_{i}$, regression coefficient; $\epsilon_{i}$, normal distributed random variable with means; zero and variance $\delta^{2}$.

The biological value (BV) was analysed after a curvilinear model:

$$
Y_{i}=\beta_{0}+\beta_{i} X_{i}^{2}+\beta_{2} X_{i}^{2}+\epsilon_{i}
$$

Where $i$, number of treatments; $Y_{i}$, dependent variable (i.e. Bv); $X_{i}$, independent variable; $\beta_{0}$, intercept; $\beta_{i}$, first order regression coefficient; $\beta_{2}$, second order regression coefficient; $\epsilon_{i}$, normal distributed random variable with mean zero and variance $\delta^{2}$. 
Table 2. Expt 3. Protein quality of various combinations of egg and potato proteins expressed as true protein digestibility (TD), biological value (BV) and net protein utilization (NPU)

\begin{tabular}{llllll}
\hline \hline & \multicolumn{2}{c}{ Protein source } & & & \\
& Egg & Potato & TD & BV & NPU \\
\hline 100 & 0 & 0.96 & 0.98 & 0.94 \\
90 & 10 & 0.96 & 0.98 & 0.94 \\
80 & 20 & 0.95 & 0.97 & 0.92 \\
70 & 30 & 0.94 & 0.95 & 0.90 \\
60 & 40 & 0.94 & 0.93 & 0.87 \\
50 & 50 & 0.94 & 0.93 & 0.87 \\
40 & 60 & 0.92 & 0.89 & 0.82 \\
30 & 70 & 0.91 & 0.87 & 0.79 \\
20 & 80 & 0.90 & 0.84 & 0.75 \\
10 & 90 & 0.89 & 0.81 & 0.72 \\
0 & 100 & 0.88 & 0.77 & 0.68 \\
SEM & & 0.004 & 0.003 & 0.004 \\
\hline \hline
\end{tabular}

\section{RESULTS}

The amino acid composition of each protein, together with the relative BV are presented in Table 1. The Table also gives the results of the statistical analyses of the BV obtained when the concentration of the single amino acid was doubled in egg and barley protein.

Expt 1. The effect of doubling the single amino acid concentration in egg protein A doubling of the concentration of the single amino acid in an egg-protein diet had in most instances only a marginal effect on protein utilization. Only in the instance of arginine was a distinct reduction obtained. BV decreased from 0.99 for egg protein alone to 0.92 when the arginine content was doubled. However, as differences in BV of 0.02 were statistically significant, several of the amino acid supplements had a significant negative effect on the BV. This was the situation for the branched-chain amino acids valine, isoleucine and leucine, the basic amino acids lysine and histidine, and tyrosine and cystine.

\section{Expt 2. The effect of doubling the single amino acid concentration in barley protein}

The utilization of barley protein was relatively more affected by dietary excess of amino acids than was the situation with egg protein. However, addition of the most limiting amino acid in barley protein, lysine, had a significant positive effect on the BV. Several of the other amino acids (especially those present in the highest concentration in barley protein) had a significantly negative effect on the BV when their content was doubled. This was most pronounced for glutamic acid and proline.

\section{Expt 3. Effect of various combinations of egg and potato proteins on protein utilization} From Table 2 it can be seen that the TD decreased linearly with increasing amounts of potato protein in the diets. There was a similar negative effect of potato protein on the relative BV. However, these values decreased curvilinearly (Fig. 1) with increasing amounts of potato protein in the diets.

\section{DISCUSSION}

The results provide useful information regarding the effect of a moderate dietary surplus of single amino acids on protein utilization. In agreement with Harper (1974) the present 


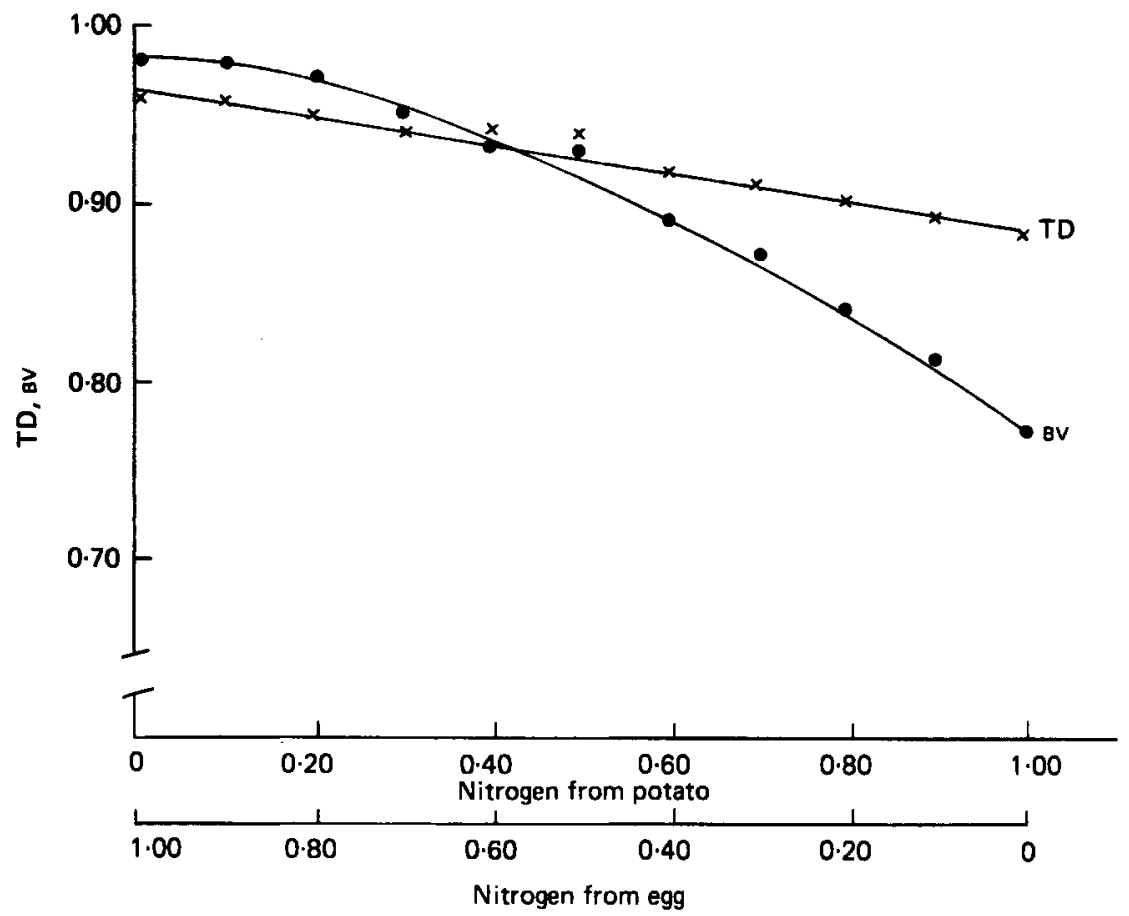

Fig. 1. Protein quality of food mixtures when increasing amounts of egg protein were replaced by potato protein. True digestibility $(T D)=0.970-0.088 \times$ nitrogen from potato protein; $R: 97.69$. Biological value (Bv) $=0.978-0.041 \times \mathrm{N}$ from potato protein $-0.167 \times(\mathrm{N} \text { from potato protein })^{2} ; R^{2} 99.66$.

work shows that a high-quality protein (egg) is much less affected by excess of a single amino acid than is a protein source of poorer quality (barley).

Expt 1. When egg protein was used as a basal diet the results indicated that an antagonism was provoked by an amino acid excess, in which there was a reversal by a structurally-similar amino acid. Thus, leucine, isoleucine and valine all had a significant effect on BV. The antagonism between these three amino acids has been discussed by Harper (1964). He showed that in a basal diet, adequate in amino acids, an excess of isoleucine and valine caused a growth depression in rats that was prevented by additional leucine even if leucine was not the limiting amino acid. Thus, Kamin \& Handler (1952) found that isoleucine absorption from the intestine was depressed when administered together with leucine. A surplus of lysine, arginine and histidine, the basic amino acids, had a negative effect on protein utilization. Jones (1962) showed also that excess of lysine apparently increases the arginine requirement of the chick and that a similar effect can be demonstrated in the rat. Furthermore, Harper (1974) showed that an excess of tyrosine in rats fed a low-protein diet, can cause a specific toxic syndrome with histopathological changes in skin, pancreas, liver and testes. The non-essential amino acids, glutamic and aspartic acids, present in the highest concentrations had no adverse effect on BV. This is, as discussed by Bender (1961), probably due to the fact that egg protein contains a relative excess of essential amino acids, some fraction of which is converted to non-essential amino acids, without loss of BV.

Expt 2. In the barley-based diet an excess of several of the dispensable amino acids apparently had a significant negative influence on protein utilization. However, the reason for the reduction in BV is assumed to be partly due to a dilution effect of the protein quality together with an antagonistic effect. This assumption is based on the fact that the amino 
acids present in highest concentrations in barley protein (glutamic acid, proline) also had the highest negative effect on the BV. Lysine, the first limiting amino acid in barley protein, had, as expected, a positive effect on protein utilization. The explanation of the distinct adverse effect of excess arginine when barley protein is fed is probably the same as that discussed in relation to Expt 1 . There exists an interaction between this amino acid and lysine (Kadirval et al. 1974).

The conclusion from Expts 1 and 2 is that protein utilization in growing rats can be affected by a $100 \%$ increase of a single amino acid in the diet, even with high protein quality (egg). This finding is in agreement with those made by Woodham \& Deans (1977) and Brewer et al. (1978) with growing chicks. In other words, both the amounts and proportions of amino acids determine the effectiveness of dietary proteins in meeting the animal's needs. However, it should be stressed that in the present work the rats were fed under the optimum protein level for maximum growth. On the other hand, the amino acid additions were relatively low compared to the doses used by Harper (1974). The question is whether the deviations from the ideal in the amino acid patterns of common food proteins were great enough to cause adverse effects. Expt 3 was performed in an attempt to illustrate this problem.

However, the results obtained with various combinations of egg and potato proteins did not support the findings of Kofrányi \& Jekat (1964) and Kofrányi (1972) that there is a distinct minimum for the protein requirement of young men at a certain combination of two protein sources. Kofrányi \& Jekat (1964) and Kofrányi (1972) found, for example, that the most favourable mixture of egg and potato proteins is $36: 64$, whereas we found a curvilinear decrease in BV with increasing concentrations of potato protein in the diets. In other words, no combinations of egg and potato proteins gave a better utilization than egg protein alone. However, it must be stressed that in the present work fast growing rats were used, i.e. the protein quality was tested at maintenance and growth whereas the German workers used young adults and tested for minimum protein requirement.

The discussion of amino acid requirements and nutritive values of dietary proteins has indicated that the pattern of amino acid required for growth may differ from that required for maintenance. Mitchell \& Beadles (1950) demonstrated that relatively small amounts of lysine are required for maintenance in the rat compared with the amounts needed for growth. Based on this assumption egg protein, rich in methionine, should also be more ideal at maintenance level than potato protein being very low in methionine.

The authors wish to thank Lisbeth Sejersen, Carlsberg Research Laboratory, for advice on the statistical analyses.

\section{REFERENCES}

Association of Official Agricultural Chemists (1965). Official Methods of Analysis of the Association of Official Agricultural Chemists. Washington DC: Association of Official Agricultural Chemists.

Bender, A. E. (1961). Nat. Acad. Sci.-Nat. Rec. Counc. Washington DC Publ. 843, 407.

Brewer, M. F., Halvorson, J. D. \& Clark, H. E. (1978). Am. J. clin. Nutr. 31, 786.

Dunnett, C. W. (1964). Biometrics 20, 482.

Eggum, B. O. (1968). Acta agric. scand. 18, 127.

Eggum, B. O. (1973). Natl Inst. anim. Sci. Copenhagen. Beretn. 406.

Harper, A. E. (1964). In Mammalian Protein Metabolism, vol. 2 [H. N. Munro and J. B. Allison, editors]. New York and London: Academic Press.

Harper, A. E. (1974). In Nutrients in Processed Foods, Proteins [P. L. White and D. C. Fletcher, editors]. Acton, Massachussetts: Publishing Sciences Group. Inc.

Harper, A. E., Benevenga, N. J. \& Wohlhueter, R. M. (1970). Physiol. Rev. 50, 428.

Jones, J. D. (1962). Fedn Proc. Fedn Am. Socs exp. Biol. 21, 1.

Kadirval, R., Vohra, P. \& Kratzer, F. H. (1974). J. Nutr. 104, 1127.

Kamin, H. \& Handler, P. (1952). Am. J. Physiol. 169, 305. 
Kofrányi, E. (1972). Melsunger Med. Mitt. 46, 15.

Kofrányi, E. \& Jekat, F. (1964). Z. Physiol. Chem. 335, 166.

Mason, V. C., Bech-Andersen, S. \& Rudemo, M. (1980). Z. Tierphysiol. Tierernähr. Futtermittelk. $43,146$.

Mitchell, H. H. \& Beadles, J. R. (1950). J. Nutr. 40, 25.

Waldroup, P. W., Mitchell, R. J., Payne, J. R. \& Hazen, K. R. (1976). Poult. Sci. 55, 243.

Woodham, A. A. \& Deans, P. S. (1977). Br. J. Nutr. 37, 289. 